\title{
A Study on Student Satisfaction in Pakistani Universities: The Case of Bahauddin Zakariya University, Pakistan
}

\author{
Muhammad Nauman Abbasi \\ Lecturer, Institute of Management Sciences \\ Bahauddin Zakariya University, Multan, Pakistan \\ E-mail: abbasimna@bzu.edu.pk
}

Ali Malik

Senior Lecturer, Department of Accounting, Finance \& Economic

University of Hertfordshire Business School, United Kingdom

E-mail: m.a.1.malik@herts.ac.uk

Imran Sharif Chaudhry (Corresponding author)

Associate professor, Department of Economics

Bahauddin Zakariya University, Multan, Pakistan

E-mail: imranchaudhry@bzu.edu.pk

Muhammad Imdadullah

Department of Statistics

Bahauddin Zakariya University, Multan, Pakistan

Received: October 19, $2010 \quad$ Accepted: February 12, $2011 \quad$ doi:10.5539/ass.v7n7p209

\begin{abstract}
This study measures the level of student satisfaction with current services offered by Pakistani universities. The exploration and comparison of possible differences in terms of level of satisfaction across gender and various programs/disciplines formulate key objectives. General survey guided by well structured questionnaire through connivance sampling has been administered across a valuable sample of 401 students. Bahauddin Zakariya University (BZU) has been selected as sample case and data was collected from eighteen different disciplines and/or programs. Ten major constructs i.e. teaching, administrative/management support, transportation, library, computer labs \& general labs, accommodation, medical; sports, prayer/religious facilities, and class room facilities were used. Mean analysis reflect student dissatisfied with many core services \& facilities like teaching, administrative support, library, labs, accommodation, medical, and sports, while satisfaction has been reported only in three augmented areas like transportation, class room and prayer facilities. Quite interestingly, no significant differences of opinion have been recorded among male or female respondents. Overall, satisfaction level is alarming low and results indicate dissatisfaction of university students on educational services offered by Pakistani universities.
\end{abstract}

Keywords: Students' satisfaction, Higher education, University services

\section{Introduction}

The aim of this paper is to determine satisfaction level of the students studying in Pakistani universities. As a matter of fact, student satisfaction has never been considered as an issue of importance by educational authorities nor regarded as a matter of survival by higher education institutions. This is evident form the fact that the impact of educational services provided by a university on the satisfaction level of its students has largely been an area 
that remains unexplored. Higher education institutions especially universities are like practice grounds where students learn and acquire all necessary skills and abilities that potential employers out there in job market sought. To ensure that this is the case, universities tend to bundle their offerings which includes; i). core services i.e. knowledge, intellectual abilities, interpersonal skills, and communication skills, ii). actual services i.e. degrees like undergraduate, graduate and postgraduate through regular teaching and research, and iii). augmented services including infrastructure i.e. building, transportation/logistics facilities, libraries, labs, computer labs, hostel/boarding facilities, medical, sports, and class room facilities coupled with administrative support. It can be convincingly argued that student satisfaction with tangible and intangible offering at universities is vital for them to acquire those skills and abilities that can satisfy needs of those next in the chain i.e. employers and society.

In Pakistan, higher education institutions are under immense pressure since the establishment of Higher Education Commission (HEC). The HEC initiated reforms in 2002 providing universities with necessary resources like unlimited access of digital libraries, high speed internet and incredible range of local and international research scholarships programs. These reforms have changed the educational climate of the country while technology has helped to improve the range of teaching and learning tools. On one side the Commission is facilitating higher education institutions, and on the other side working for the enhancement of quality of education in the country. This double edge sword i.e. higher education expansion and high quality of higher education has spurred a drive to improve and enhance quality standards. Resultantly, this has created a distinct "sphere of opportunities", simulated among students, teachers and the market. The authors are of the view that this sphere of opportunities, if follows the principle of quality, will leads to educational revolution in the country.

In Pakistan, there are 124 universities of which $68(55 \%)$ are in public sector, whereas $56(45 \%)$ are in private sector. The total enrolment in the universities is 741,092 of which $637,037(86 \%)$ is in public sector, whereas, $104,055(14 \%)$ is in private sector. The total male enrolment in the universities is 398,967 (54\%), whereas, the female enrolment is $342,125(46 \%)$. The total teachers in the universities are 46,893 , out of which $38,266(82 \%)$ are in public and 8,627 (18\%) are in private sector (Statistics, 2007-2008). Observing the facts, considerable students i.e. 741,092 have been enrolled during the academic year 2007-2008. The question underlying in this study is whether Pakistani students are satisfied with the academic, administrative, and logistics support provided by their respective higher education institution. To measure personal satisfaction of the university students, this study has been initiated to empirically measure the phenomenon taking Bahauddin Zakariya University, Multan (BZU) as case.

\section{Literature Review}

Kotler et al. (2009, p.120) define satisfaction as 'a person's feeling of pleasure that result from comparing a product's perceived performance (or outcome) to their expectation'. It means if the performance matches the expectation, the customer will be satisfied. In the context of higher education, the matter of satisfaction is what students expect from their educational institution, in fact, everything that makes them eligible to become productive and successful person in their practical lives. Reid (2008) has classified few basic characteristics that employers normally seek from university graduate. These include knowledge, intellectual abilities, ability to work in modern organizations, interpersonal skills, and communication skills (Reid, 2008). In addition, there are other invisible characteristics required by the market and that include: willingness to learn, be participative and positive to work in teams, problem solving skills, analytical abilities, leadership qualities, adaptability, flexibility, ability to summarize key issues, and last but not least the ability to be productive and loyal team/organizational member. The attainment of these skills and abilities is what parents expect when they decide to send their children for higher education in universities.

The question under consideration here is if university graduates are provided necessary facilities that make their experience conducive and attainment of necessary skills and abilities possible. This is crucial not only to students' individual success but the success of economy of the country on the whole as well. In this regard, Umbach and Porter (2002) argued that institutional impact on the students' outcome is still unknown, and if anything is known, that is somewhat contradictory. Moreover, it is worth mentioning that different academic disciplines vary in term of their application of practical problems, cognitive processes, faculty time commitment and scholarly output. Hence, it is quite difficult to conclude institutional impact on students' outcome. However, among the earlier researchers, Cameron and Ettington (1988) and Hartnett and Centra (1977) measured the impact of departmental culture and climate on students' leaning and satisfaction.

Much of the current knowledge on student satisfaction can be traced from studies during a period of unrest in the late 1960s and early 1970s (Betz et al. 1970; Pervin, 1967). Interestingly, the focus of these early studies was the 
level of satisfaction as opposed to cause of satisfaction (see for example, Bean and Bradley, 1986). In literature, there exists an interesting debate suggesting that students' expectation build prior to enrolment in a college or university, while satisfaction exists during his/her stay in college or university. For example, Palacio et al. (2002) suggest that student expectation normally build even before entering the university. The image of an institution affects students' mindset that in turn affects their decision to enroll in that particular institution that later on directly affects students' satisfaction with the institution. However, Carey et al. (2002) stressed that satisfaction actually covers issues of students' perception and experiences during their academic years. This has been supported by Kara (2004) who employed empirical data and conceptual model to prove that students' college experience is positively related to their satisfaction and intentions to stay at college or university. Earlier, Keaveney and Clifford (1997) have presented students satisfaction and retention model. According to this model, faculty, advising staff and class room facilities normally shape student practical college experience and therefore considered key satisfaction and retention components.

Researchers have also measured students' satisfaction in context of many tangible and intangible elements and characteristics. For example, Feldman and Newcomb (1969) and Pascarella and Terenzini (1991) have explored relationship between student learning experiences and their learning, development and satisfaction. Pike (1994) and Pace (1979) have suggested alumni satisfaction as an excellent tool for assessing the effects of educational institution on students. Based on the studies of Pascarella and Terenzini (1991) and Umbach and Porter (2002), it is stated that intellectual and personal developments are among key satisfaction outcomes of educational institutions. Moreover, they found variables like faculty contact with students, research emphasis, and proportion of female students had significant impact on student satisfaction. Ewell (1989) has observed negative correlation between institutional culture and its impact on student performance.

The contradiction exits in literature regarding relationship between grades and students satisfaction. Authors like Liu and Jung (1980) and Pike (1991) have observed moderate relationship, while Bean and Bradley (1986) found no relationship at all. However, Centra and Rock (1983) and Lavin (1965) observed significant relationship between grades and student satisfaction. On the other hand, limited attempts have been made to measure impact of gender, ethnicity, race, religion, and migrations from one educational institution to another, on student satisfaction. However, existing evidence reports less satisfaction among female students as compared to male students (for example, Rienzi et al. 1993).

Numerous studies have addressed the issue of service quality and student satisfaction. For example, Fitri et al. (2008) have observed service quality dimension i.e. tangibility, responsiveness, reliability, assurance, and empathy as positive contributors towards student satisfaction. Some other authors like Bigne et al. (2003), Ham and Hayduk (2003) and Elliot and Shin (2002) have reported significant relationship between service quality i.e. service reliability, responsiveness, empathy, assurance, tangibility etc and satisfaction in higher education settings. Spreng and Mackoy (1996) reported that perceived service quality is an antecedent to satisfaction.

Faculty continues to be the most significant influence on student experience and satisfaction in universities. In this regard, universities have adopted student evaluation of teaching effectiveness to enhance student satisfaction. Student evaluation of teaching (SET) is among the most frequently used performance measurement instruments used by higher education institutions across the world (Pounder, 2007; Stratton, 1990). Student evaluation of teaching (SET) questionnaire is a control device used to measure teaching effectiveness as stated by concerned students (Crumbley et al. 2001). Historically, a number of studies confirmed that student teaching evaluation has provided reasonably valid multidimensional measures (Holtfreter, 1991; Marsh \& Roche, 1997; McKeachie, 1987). The main aim of the SET is to measure the teaching performance/effectiveness of faculties at a university. Moreover, this technique is used in educational institutions to assess the capabilities and competencies of academic staff and as a result, assessment score depicts that on what basis students perceive their teachers in their minds that directly affects their satisfaction.

In context of Pakistan, majority of the studies have focused on the ways to improve the quality of higher education, unfortunately, no significant study has probed the issue of student satisfaction. For example, Hanif et al. (2008) examine the use of balance scorecard to enhance accountability and performance in higher education institutions concluding that long-term vision through consistent performance evaluation is the key to enhance performance in higher education. Reid (2008), while making comparison between higher education in Scotland and Pakistan, highlighted industry as a source of evaluation parallel to internal evaluation system. Moreover, he suggested an increase in the number of PhD qualified teachers throughout the country. Owais and Akber (2008) commented how to improve research/PhD education in the country. Aurangzeb (2008) presented a work integrated learning model for students. The Model suggests the role of three key educational players i.e. students, higher education institutions, and industry to improve education and student satisfaction in the country. Hafeez 
and Fatima (2008) have highlighted the importance of strategic partnership between universities and industry. They have presented a conceptual model with the focus to transform the kind and level of collaboration between universities and industry. Nasira et al. (2008) have presented comprehensive debate on the importance of international ranking and its impact on student mindset while selecting a college or university for higher education. They have suggested that college or university ranking should not be the only criteria to select any institution for higher education rather student must gather necessary other information before making final selection.

From the existing literature, it is evident that there is a need to administer a systematic research to measure the important issue of student satisfaction in Pakistani universities. From literature, three different constructs i.e. teaching, administration/management, and support \& augmented facilities have been used as major variables to measure student satisfaction in this study.

\section{Research Methodology}

As stated above, this study aims to measure student satisfaction in Pakistani universities. Bahauddin Zakariya University (BZU) in Multan has been selected as a sample case because the university is a public sector university and is currently offering a wide range of programmes of studies under various faculties at postgraduate and undergraduate levels. University has significant population (on board students) from neighboring countries as well. Six major faculties are playing pioneering role in spreading education across the country and act as catalysts for socio-economic development of the country. The faculties are: Faculty of Arts \& Social Sciences, Faculty of Islamic Studies \& Languages, Faculty of Commerce, Law \& Business Administration, Faculty of Science \& Agriculture, Faculty of Pharmacy, and Faculty of Engineering. Hence, the university was selected as sample case and data was collected from current students enrolled in eighteen different disciplines and/or programs representing both postgraduate and undergraduate levels.

First construct under observation was 'teaching' that is considered a core activity at higher education institutions. Nineteen different variables were used to measure student satisfaction of this construct. The variables under observation were; teachers communication, lecture delivery skills (qualitative subjects), lecture delivery skills (quantitative subjects), research activities, nature of class assignments and tasks, examination and grading (quantitative subjects), examination and grading (qualitative subjects), examination procedures, teacher's attitudes towards class, teacher's respect for class, extra consultation, extra reading material, feedback on assignments, permanent senior teachers, permanent junior teachers, permanent male teachers, permanent female teachers, visiting male teachers, visiting female teachers.

Second construct under observation was 'administrative support'. In addition to teaching, administrative activities are necessary to facilitate the process of developing necessary skills and providing exposure to students in accordance with market demand. The administrative construct has been operationalize through eight different variables that were; behavior of head of department and programme coordinators, behavior of clerical staff, administrative support of head of department and programme coordinators, administrative support of clerical staff, extracurricular activities, banking facilities, restaurant facilities at the campus, and prayer facilities.

Third construct under observation was 'augmented facilities' and variables used to measure this were; transportation and logistics facilities, library, computer labs, general labs, student accommodation facilities, medical facilities, sport facilities, and class room facilities. All these concepts have been further probed through different variables like transportation and logistics has been measured through, availability of buses, route timings, and behavior of the drivers \& conductors. Satisfaction from library facility has been measured through seven different variables including availability of core text books, availability of supporting books, availability of research journals, availability of newspaper \& magazines, library timings, facilities at central library, behavior of the library staff. Next facility computer labs were measured through variables like availability of enough computers, internet availability and speed, behavior of lab attendants, computer labs timings, and availability of e-journals. Similarly, availability of required equipments, behavior of lab attendants, and lab timings were used to measure the satisfaction of the concerned students.

To measure students satisfaction about hostel and boarding, four different variables were used, which are; availability \& condition of rooms, mess and dining, behavior of hostel staff, and overall study environment. In addition, medical facility was measured through different variables which are; availability of doctors, availability of medicines, availability of ambulances, and availability of emergency staff and medicines. Next concept sports facilities were measured through four different variables which are; availability of sports grounds, coaching facilities, availability of sports equipments and sport development opportunities. Last augmented facility under 
observation was class room facilities, which have been measured through variables i.e. class size, class timings, availability of multimedia, air conditions, and furniture \& fixture.

All variables were measured on Likert Scale of 1 to 4 where: $1=$ extremely satisfied; $2=$ satisfied; $3=$ dissatisfied, and $4=$ extremely dissatisfied. High value of Cronbach's Alpha (0.92) reflects high reliability of instrument. Table -1 , presents response rate as per programs/disciplines and gender. High response variations have been recorded across different faculties and programmes of studies. A total of four hundred and eighteen (418) responses were collected, however, seventeen (i.e. 4.1\%) were discarded because respondents have neither mentioned gender nor their programme of studies, therefore, the final sample size turns out to be four hundred and one (401). Of four hundred and one, 191 (45.7\%) respondents were male, while 210 were female i.e. 50.2\%. On the other hand, 218 (52.2\%) respondents were studying for undergraduate degree, while $183(43.8 \%)$ were studying for postgraduate degree.

Based on literature synthesis, well structured questionnaire have been formulated to know the satisfaction level of student studying in different programs at different levels. Undergraduate and postgraduate students currently enrolled in any semester of forty different departments were considered as unit of analysis. To make it a systematic process, researchers tried to manage an enrollment list (a sample frame) in all programmes of studies of all concerned departments. However, in some instances administrative staff refused to provide the list of students due to confidentiality issues. Resultantly, questionnaires get filled through non probability connivance sampling. Data have been collected from students enrolled during session Fall-2009.

\section{Results \& Discussion}

The primary aim of this study was to measure student satisfaction in Pakistani Universities. The three construct used to do so were teaching, administrative support and augmented facilities. The first construct applied was 'teaching' that is obviously a core activity in any education institution. Nineteen different variables were used to measure student satisfaction about teaching and related activities (please see section 3 of Table -2 , for detail). With the exception of few variables, overall mean values of the variables regarding this construct reflected student dissatisfaction of existing teaching methods and techniques. Mean values of different variables enhancing university student satisfaction are; teachers communication (mean value of 2.34), lecture delivery skills of qualitative subjects (mean value of 2.48), examination procedures (mean value of 2.50), teachers attitudes towards class (mean value of 2.49), teachers respect for class (mean value of 2.30).

It is observed that several key areas need keen attention of faculty members, head of the departments, deans and vice chancellor. The areas are; lecture delivery skills of quantitative subjects (mean value of 3.20), provision of feedback on assignments (mean value of 2.59), number of permanent (full time) senior teachers (mean value of 2.59), number of permanent (full time) junior teachers (mean value of 2.57), research activities (mean value of 2.96), nature of class assignments \& tasks (mean value of 3.05), examination and grading of qualitative subjects (mean value of 2.90), extra reading material (mean value of 3.04), examination and grading of quantitative subjects (mean value of 2.77), extra consultation time by teachers (mean value of 2.74), permanent (full time) male teachers (mean value of 2.87), permanent (full time) female teachers (mean value of 2.95), visiting (part time) male teachers (mean value of 2.96), visiting (part time) female teachers (mean value of 3.04).

Results of mean analysis clearly reflect that students are largely dissatisfied with their teachers' communication skills (language used for lecture). Moreover, to probe the satisfaction level of the university students with lecture delivery skill of their teachers, questions were included as per classification of curriculum i.e. quantitative \& qualitative courses. Students have unanimously declared that they are dissatisfied with the delivery skills of teachers of quantitative courses as compared to qualitative ones. Perhaps, this reflects positive attitude of Pakistani students towards qualitative subjects as compared to quantitative subjects; however, there is a need to improve delivery skills of teachers of quantitative courses. Moreover, as there is no visible difference of opinion among male and female students studying either at undergraduate or postgraduate levels, the results strengthen the above discussion.

In addition, lesser satisfaction about research activities has been reported by undergraduate students as compared to postgraduate students, which validates the fact that strong research activities are normally required and conducted at higher level in Pakistani universities. However, mean analysis depicts that students are dissatisfied with the nature of research carried out in different disciplines. This situation is quite alarming for higher education authorities, particularly Higher Education Commission (HEC) who is striving for quality research in Pakistani universities. Quite interestingly, high dissatisfaction was reported by male respondents regarding nature of class assignments, supporting the view that teachers (in Pakistani universities) normally give easier tasks and assignments to female students which is gender discrimination by the teachers. Similarly, postgraduate 
students are more dissatisfied with the nature of assignments as compared to undergraduate ones. Perhaps, this dissatisfaction is because of the fact that students failed to recognize visible differences in term of nature and quality of assignments they had performed during their undergraduate studies from the one they are doing during their postgraduate studies. Overall results regarding research activities invite serious attention of Higher Education Commission of Pakistan in general and management of the BZU University in particular.

Lesser dissatisfaction with grading \& marking of quantitative courses as compared to qualitative ones endorses natural response and perhaps mature attitude of students. However, overall dissatisfaction on grading and marking reflects distrust on the assessment style of university teachers. On the other hand, satisfactory mean score on examination procedure reflects valuable trust on new measures taken by universities to enhance examination standards. In these variables, no visible difference of opinion has been reported among male and female students. The trust on examination procedure while distrust on grading \& marking reflects university commitment to enhance education standards while provoke serious thinking to do on the paper and coursework marking style of teachers. Next, the mean scores depict positive attitude of the teachers towards their classes. However, allocation of appropriate time for consultation has been reported as a dissatisfactory variable. The results are in fact conceivable, because of large population of students in Pakistani universities making it difficult to academic staff to allocate equal additional support for all students causing dissatisfaction at individual levels.

Finally, it can be observed from the results that overall students are dissatisfied with academic faculties irrespective they are senior or junior, male or female and permanent or visiting. Similarly, dissatisfaction is quite high in respect of visiting faculty members which indicates distrust on pathetic recruitment policy of university. It is recommended that authorities must hire permanent teachers of high caliber with excellent academic competencies rather than relying on contract or visiting teaching staff. In this regard, new recruitment policy from Higher Education Commission (HEC) can bring about a positive change provided it is implemented with true spirit and monitored consistently. Moreover, if highly required, respective Deans and Head of the Department must ensure to hire highly qualified and experienced visiting teachers. A clear policy needs to be chalked out and implemented in this respect.

Here it is worth mentioning that the sample case i.e. Bahauddin Zakariya university is situated in Southern Punjab. In this part of the country hiring high caliber, self-motivated and highly qualified individuals has always remained a challenging job for university management. This region is largely remote and most of the qualified individuals prefer living and working in metropolitan cities of Pakistan like Islamabad, Lahore and Karachi. Secondly, BZU is a public sector university and can't offer competitive salaries and financial incentives. Moreover, lack of motivation to work in a university, biased behavior of university management, extra work load without remuneration and limited training and personal development opportunities are among the key reasons restricting the entry of competent individuals in education sector. In addition to these, university is distantly located from city centre making it inconvenient for visiting faculty members to come all the way for few hours work and hence low level of interest is recorded. Moreover, university does not have an incentive plan in policy in place to attract high quality professionals to come to university.

Second construct under observation were the 'administrative support'. Individual mean analysis depicts that there some fundamental facilities are in place and are currently responsible for overall student satisfaction. These are; prayer facilities available at campus (mean value of 2.18) and facilitation by university management for extracurricular activities (mean value of 2.41). For these variables, no significant difference of opinion has been recorded among male and female students, as well as at level of studies i.e. undergraduate or postgraduate. It is quite interesting that branches of two well-reputed national banks are operative at campus, still surprisingly; students have reported dissatisfaction with the current banking facilities.

On the other hand, behavior of the Chairman of department and Programme Coordinators (mean value of 2.83), administrative support of Chairman and Coordinators (mean value of 3.00), administrative support of clerical staff (mean value of 3.27), overall mess and dinning facilities available at campus (mean value of 2.76) are emerged as critical factors. In this regard, female students in particular have reported higher level of dissatisfaction with behavior and dealing of clerical staff which is astonishing as well as quite alarming. Results require immediate attention of university authorities and concrete steps need to be taken to improve the behavior of the administrative staff. It is also recommended that the relevant authorities must take proper measures to enhance the overall level of administrative support.

Third construct under observation was 'augmented facilities' which was measured using following variables; transportation \& logistics facilities, library, computer labs, labs, hostel/boarding facilities, medical facilities, sport facilities, and class room facilities. Transportation \& Logistics facility have been measured through factors 
like availability of buses (mean value of 2.50), route timings (mean value of 2.25), and behavior of the drivers \& conductors on buses (mean value of 2.88). Overall mean values regarding transportation facilities reflect student satisfaction with the available transportation facilities offered by university. It is significant to note that the behavior of bus drivers \& conductors are somewhat problematic to student satisfaction. In this regard, male students seem to be more dissatisfied with the behavior of bus staff as compared to female students. Second augmented facility under observation was library and student satisfaction about library facilities has been measured through seven different variables i.e. availability of core text books (mean value of 2.68), availability of supporting books (mean value of 2.70), availability of research journals (mean value of 3.06), availability of relevant newspaper \& magazines (mean value of 2.42), library timings (mean value of 2.69), facilities at central library (mean value of 2.80), behavior of the library staff (mean value of 2.67). Outcomes clearly depict that students are dissatisfied with the current library facilities; moreover, they have exhibited notable dissatisfaction regarding availability of research journals. Again, no meaningful difference of opinion has been recorded between male and female student either studying at undergraduate or postgraduate level.

Next, availability of computers (mean value of 3.31), internet availability and speed (mean value of 3.96), behavior of lab attendants (mean value of 2.91), labs timings (mean value of 3.21), and availability of e-journals (mean value of 3.38) were used to probe student satisfaction regarding computing facilities available in various faculties. All the related variables reflect visible student dissatisfaction; therefore, this situation invites wholehearted inertest of Higher Education Commission (HEC) and keen attention of university's higher authorities. No significant difference of opinion has been observed among male \& female student either studying at graduate or postgraduate level.

Some disciplines like natural sciences, agriculture and engineering require labs equipped with latest equipments for practical demonstration and advance research. So, labs has been taken as a core facility to observe student satisfaction and the construct was probed through variables like; availability of required equipments (mean value of 3.22), behavior of lab/s attendants (mean value of 2.74), and labs timings (mean value of 2.70). Again results reveal that students are dissatisfied with the available equipments, either the equipments are not sufficient or they are outdated. Student studying at postgraduate level showed more dissatisfaction regarding availability of equipment as compared to undergraduate ones. Hence, it can be suggested that better research outcome can be expected if postgraduate students are provided with latest lab and research equipments.

To measure student satisfaction about hostel \& boarding facility, four different variables were used, which are; availability \& condition of rooms (mean value of 3.39), mess/dining facilities within hostels (mean value of 3.63 ), behavior of hostel staff (mean value of 3.26), and overall study environment (mean value of 3.41). Overall results indicate highest level of dissatisfaction about hostel \& boarding facilities offered by university. Although overall dissatisfaction is very high, however, results reflect that female students are comparatively more dissatisfied regarding availability of rooms, mess/dinning facilities and behavior of the hostel staff as compared to male students. In the same construct (hostel/boarding), undergraduate students express higher level of dissatisfaction as compared to their postgraduate counterparts.

Next, medical facility was measured through four different variables which are; availability of doctors (mean value of 3.15), availability of medicines (mean value of 3.21), availability of ambulances (mean value of 2.86), and availability of emergency staff \& medicines (mean value of 3.30). Again, results indicate student dissatisfaction. Here it is important to note that university has separate medical centers for male and female students. In addition to this, university has deputed two full time male doctors and one lady doctor to ensure adequate level of medical facility around the clock. However, dissatisfaction signals either lack of awareness of this among students or poor provision of facility in reality.

Sports play a significant role to foster healthy mind. As stated earlier sports facilities were measured through four different variables which are; availability of sports grounds (mean value of 2.68), coaching facilities (mean value of 3.40), availability of sports items \& equipments (mean value of 3.62) and sports development opportunities (mean value of 3.33). Outcomes indicate that university is lacking in terms of sport opportunities, however, new sports complex is under construction that may change experience of future students of university. Here, it is important to note that no meaningful difference of opinion has been observed among male and female student either studying either at undergraduate or postgraduate level.

Last augmented facility under observation was class room facilities, which have been measured through variables like class size (mean value of 2.23), class timings (mean value of 2.34), availability of multimedia (mean value of 3.82), air conditioning (mean value of 3.17), and furniture \& fixture (mean value of 2.44). Except two key facilities that are multimedia and air conditioning, students are satisfied with the class room size, class 
timings and furniture \& fixtures. Again, no significant difference of opinion has been recorded among male \& female student either studying at undergraduate or postgraduate level.

\section{Conclusion and Recommendations}

Overall results reveal that university students are satisfied with available transportation facilities, class room facilities, religious (prayer facilities) and facilitation for extra-circular activities. On the other hand, students express their dissatisfaction regarding teaching techniques and methods, behavior of administration \& staff, computer facilities, library \& connected facilities, general labs, hostel/boarding facilities and sports opportunities, mess/dinning available at campus.

Based on above stated facts, it can be concluded that majority of the students studying in Pakistani universities are dissatisfied with current offerings. On one hand, 'teaching' facilities including teaching methods \& techniques are outdated while on the other hand, lack of administrative support increases student dissatisfaction. Here, it is worth mentioning that despite of the fact that Higher Education Commission (HEC) is consistently introducing reforms in higher education but unfortunately these reforms are unable to create satisfaction among the graduates. Results also point out weakness in management/administration and the same is evident from the fact that universities are provided with remarkable resources (in term of infrastructure) like unlimited access of digital libraries, high speed internet and incredible range of local and international scholarships programs, however, lack of administrative interest and mismanagement has created student dissatisfaction. Similarly, lack of awareness and dissatisfaction of the students regarding available resources like internet, labs, library, medical, banking and other facilities also highlight mismanagement.

Current situation invites attention of all the educational authorities i.e. Ministry of Education Government of Pakistan, Higher Education Commission of Pakistan, Chancellors of both Public \& Private universities, Vice Chancellors \& Rectors, concerned Deans, and everyone responsible to enhance the quality \& standards of higher education in the country. This research should be considered as a first step to know the level of satisfaction of university students in Pakistan. The results of this study can be generalized, if the scope of research extends to more universities \& disciplines. Similarly, a more systematic sampling could also add to the validity of findings. Moreover, impact of satisfaction on the students' personality, market performance \& outcome, intellectual skills, capabilities needed etc. are among the key areas for future investigation.

\section{References}

Aurangzeb, C. R. (2008). Quality Assurance Model for Assessment of Work Integrated Learning at Higher Education Institution of Pakistan. Paper presented at the 2nd International Conference on Assessing Quality in Higher Education.

Bean, J. P., \& Bradley, R. K. (1986). Untangling the Satisfaction-Performance Relationship for College Students. Journal of Higher Education, 57(04), 393-412.

Betz, B. L., Klingensmith, J. B., \& Menne, J. W. (1970). The Measurement and Analysis of College Student Satisfaction. Measurement and Evaluation in Guidance, 03, 110-118.

Bigne, E., Moliner, M. A., \& Sanchez, J. (2003). Perceived Quality and Satisfaction in Multi Service Organizations: The Case of Spanish Public Services. The Journal of Services Marketing, 17(04), 420-442.

Cameron, K., \& Ettington, D. (1988). The Conceptual Foundations of Organizational Culture (Smart, J. ed. Vol. 04). Higher Education Handbook of Theory and Research.

Carey, K., Cambiano, R. L., \& De Vore, J. B. (2002). Student to Faculty Satisfaction at a Midwestern University in the United States. HERDSA, 93-97. [Online] Available: www.ecu.edu.au/conferences/herdsa/main/papers/ref/pdf/Carey.pdf.

Centra, J. A., \& Rock, D. (1983). College Environments and Student Achievement. American Educational Research Journal, 08, 623-634.

Crumbley, L., Henry, B. K., \& Kratchman, S. H. (2001). Students' Perceptions of the Evaluation of College Teaching. Quality Assurance in Education, 9(4), 197-207.

Elliot, K. M., \& Shin, D. (2002). Student Satisfaction: An Alternative Approach to Assessing this Important Concept. Journal of Higher Education Policy and Management, 24(02), 197-209.

Ewell, P. T. (1989). Institutional Characteristics and Faculty/Administrator Perceptions of Outcome: An Exploratory Analysis. Research in Higher Education, 30(02), 113-136.

Feldman, K. A., \& Newcomb, T. M. (1969). The Impact of College on Students. Jossey-Bass. 
Fitri, H. A. H., Ilias, A., Abd Rehman, R., \& Abd Razak, M. Z. (2008). Service Quality and Student Satisfaction: A Case Study at Private Higher Education Institutions. International Business Research, 01(03), 163-175.

Hafeez, S. A., \& Fatima, A. J. (2008). A Conceptual Framework For Developing Strategic Partnership Between University And Industry In Pakistan With Particular Reference to NWFP. Paper presented at the 2nd International Conference on Assessing Quality in Higher Education, Lahore.

Ham, L., \& Hayduk, S. (2003). Gaining Competitive Advantages in Higher Education: Analyzing the Gap Between Expectations and Perceptions of Services Quality. International Journal of Value-Based Management, 16(03), 223-242.

Hanif, M., Safdar, M., Hameed, M. K., \& Masood, R. (2008). Enhancing Accountability and Performance of Higher Education through Balance Scorecard. Paper presented at the 2nd International Conference on Assessing Quality in Higher Education.

Hartnett, R. T., \& Centra, J. A. (1977). The Effects of Academic Departments on Student Learning. The Journal of Higher Education, 48(05), 491-507.

Holtfreter, R. E. (1991). Student Rating Biases: are Faculty Fears Justified? The Woman CPA(Fall), 59-62.

Kara, A. (2004). Business Student Satisfaction, Intentions and Retention in Higher Education: An Empirical Investigation. $M E Q, 03$ (Fall 2004), 1-15.

Keaveney, S. M., \& Clifford, E. Y. (1997). The Student Satisfaction and Retention Model (SSRM).

Kotler, P., Lane, K. K., Koshy, A., \& Jha, M. (2009). Marketing Management - A South Asian Perspective: Pearson Publication.

Lavin, D. E. (1965). The Prediction of Academic Performance: Sage Publication.

Liu, R., \& Jung, L. (1980). The Commuter Student and Student Satisfaction. Research in Higher Education, 12(03), 215-226.

Marsh, H. W., \& Roche, L. A. (1997). Making Students' Evaluations of Teaching Effectiveness Effective: The Critical Issues of Validity, Bias and Utility. American Psychologist, 52(11), 1187-1197.

McKeachie, W. (1987). Can Evaluating Instruction Improve Teaching? in Aleamoni, L.M. (Ed.), Techniques for Evaluating and Improving Instructions(Jossey-Bass, San Francisco, CA.).

Nasira, S.-u.-R., Saringat, H. J. B., \& Azhar, S. S. (2008). Assessing Quality in Higher Education: Impact of National and International Ranking. Paper presented at the 2nd International Conference on Assessing Quality in Higher Education, Lahore.

Owais, S. M., \& Akber, S. (2008). Quality of PhD Program - Issues and Problems. Paper presented at the 2nd International Conference on Assessing Quality in Higher Education.

Pace, C. R. (1979). Measuring the Outcomes of College. Jossey-Bass.

Palacio, A. B., Meneses, G. B., \& Perez, P. J. P. (2002). The Configuration of the University Image and its Relationship with the Satisfaction of Students. Journal of Educational Administration, 40(05), 486-505.

Pascarella, E. T., \& Terenzini, P. T. (1991). How College Affects Students: Findings and Insights from Twenty Years of Research. Jossey-Bass.

Pervin, L. A. (1967). Satisfaction and Perceived Self-Environment Similarity: A Semantic Differential Study of Student-College Interaction. Journal of Personality, 35, 623-624.

Pike, G. R. (1991). The Effects of Background, Coursework, and Involvement on Students' Grade and Satisfaction. Research in Higher Education, 32(01), 15-31.

Pike, G. R. (1994). The Relationship Between Alumni Satisfaction and Work Experience. Research in Higher Education, 35(01), 15-31.

Pounder, J. S. (2007). Is Student Evaluation of Teaching Worthwhile? An Analytical Framework for Answering the Question. Quality Assurance in Education, 15(02), 178-191.

Reid, N. (2008). Quality Assurance in Higher Education in Pakistan - Focus on the Learner. Paper presented at the 2nd International Conference on Assessing Quality in Higher Education ICAQHE 2008.

Rienzi, B. M., Allen, M. J., Sarmiento, Y. Q., \& McMillin, J. D. (1993). Alumni Perception of the Impact of Gender on their University Experience. Journal of College Student Development, 34, 154-157. 
Spreng, R. A., \& Mackoy, R. D. (1996). An Empirical Examination of a Model of Perceived Service Quality and Satisfaction. Journal of Retailing, 72(02), 52-64.

Statistics, P. E. (2007-2008). Pakistan Education Statistics.

Stratton, W. O. (1990). A Model for the Assessment of Student Evaluations of Teaching, and the Professional Development of Faculty. The Accounting Educators' Journal(Summer), 77-101.

Umbach, P. D., \& Porter, S. R. (2002). How do Academic Departments Impact Student Satisfaction? Understanding the Contextual Effects of Departments. Research in Higher Education, 43(02), 209-233.

Table 1. Department under observation - response rate categorized as per program/discipline \& gender

\begin{tabular}{|c|c|c|c|c|c|c|c|c|c|c|}
\hline & \multirow[t]{2}{*}{ Faculty/Departments } & \multicolumn{2}{|c|}{ RESPONDENTS } & \multicolumn{2}{|c|}{ RESPONDENTS } & \multicolumn{2}{|c|}{ GRADUATES } & \multicolumn{2}{|c|}{ P.GRADUATES } & \multirow[t]{2}{*}{ Total } \\
\hline & & Gradate & $\begin{array}{c}\text { Post } \\
\text { Gradate }\end{array}$ & Male & Female & Male & Female & Male & Female & \\
\hline A. & \multicolumn{10}{|l|}{ Faculty of Arts \& Social Sciences } \\
\hline 1. & Department of Economics & 15 & 12 & 16 & 11 & 08 & 07 & 08 & 04 & 27 \\
\hline 2. & Department of Education & 10 & 09 & 10 & 09 & 06 & 04 & 04 & 05 & 19 \\
\hline 3. & Department of History \& Geography & Nil & 10 & 05 & 05 & Nil & Nil & 05 & 05 & 10 \\
\hline 4. & Department of Pak Studies & Nil & 11 & 06 & 05 & Nil & Nil & 06 & 05 & 11 \\
\hline 5. & $\begin{array}{l}\text { Department of Political Studies \& } \\
\text { International Relations }\end{array}$ & Nil & 10 & 05 & 05 & Nil & Nil & 05 & 05 & 10 \\
\hline 6. & Department of Mass Communication & 15 & 12 & 14 & 13 & 07 & 08 & 07 & 05 & 27 \\
\hline 7. & $\begin{array}{l}\text { Department of Applied Psychology, } \\
\text { Philosophy and Sociology }\end{array}$ & 20 & 11 & 12 & 19 & 07 & 13 & 05 & 06 & 31 \\
\hline 8. & Multan College of Arts & 11 & 12 & 04 & 19 & 03 & 08 & 01 & 11 & 23 \\
\hline B. & \multicolumn{10}{|l|}{ Faculty of Islamic Studies \& Languages } \\
\hline 9. & Department of English, Urdu \& Arabic & 14 & 15 & 05 & 24 & 02 & 12 & 03 & 12 & 29 \\
\hline C. & \multicolumn{10}{|c|}{ Faculty of Commerce, Law \& Business Administration } \\
\hline 10. & Institute of Management Sciences. & 15 & 16 & 17 & 14 & 10 & 05 & 07 & 09 & 31 \\
\hline 11. & Department of Commerce & 07 & 05 & 06 & 06 & 03 & 04 & 03 & 02 & 12 \\
\hline 12. & University Law College & 08 & 03 & 08 & 03 & 06 & 02 & 02 & 01 & 11 \\
\hline D. & \multicolumn{10}{|l|}{ Faculty of Science \& Agriculture } \\
\hline 13. & Department of Physics. & Nil & 12 & 08 & 04 & Nil & Nil & 08 & 04 & 12 \\
\hline 14. & Institute of Computing & 25 & 11 & 16 & 20 & 10 & 15 & 06 & 05 & 36 \\
\hline 15. & Department of Statistics & 07 & 04 & 04 & 07 & 03 & 04 & 01 & 03 & 11 \\
\hline 16. & $\begin{array}{l}\text { University College of Agriculture \& } \\
\text { Agri-engineering. }\end{array}$ & 18 & 18 & 21 & 15 & 10 & 08 & 11 & 07 & 36 \\
\hline E. & \multicolumn{10}{|l|}{ Faculty of Pharmacy } \\
\hline 17. & Department of Pharmacy & 08 & 12 & 09 & 11 & 02 & 06 & 07 & 05 & 20 \\
\hline F. & \multicolumn{10}{|l|}{ Faculty of Engineering } \\
\hline 18. & $\begin{array}{l}\text { University College of Engineering \& } \\
\text { Technology \& } \\
\text { Institute of Advance Material Sciences }\end{array}$ & 45 & Nil & 25 & 20 & 25 & 20 & Nil & Nil & 45 \\
\hline Total & 19 Departments & 218 & 183 & 191 & 210 & 102 & 116 & 89 & 94 & 401 \\
\hline
\end{tabular}


Table 2. Program \& gender wise mean comparison across different constructs/concepts/variables

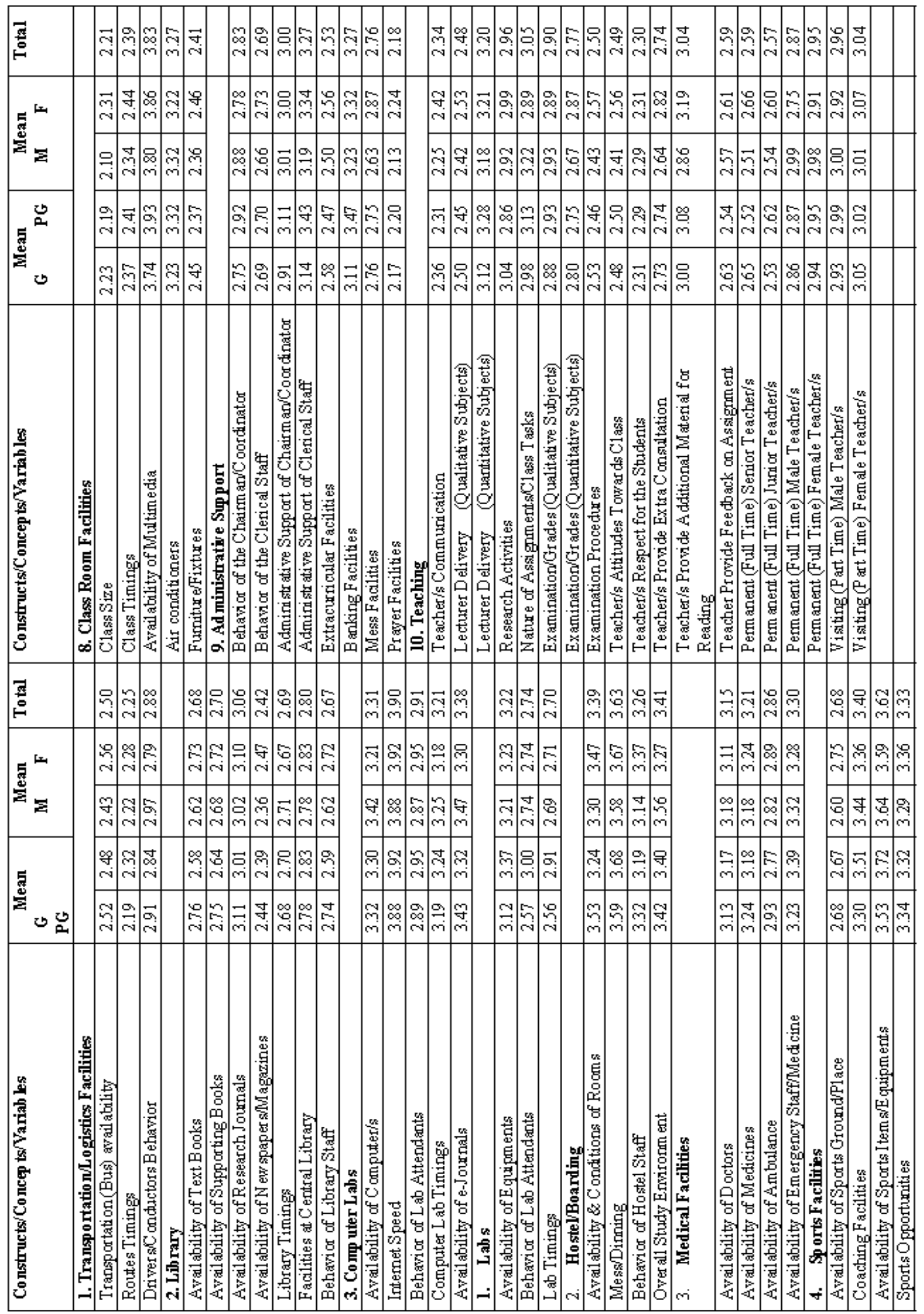

